Research Article

\title{
Research on Characteristics of Wireless Power Transfer System Based on U-Type Coupling Mechanism
}

\author{
Jia Jinliang $(\mathbb{D}$ and Yan Xiaoqiang $(\mathbb{D}$ \\ School of Mechanical Engineering, University of Science and Technology Beijing, Beijing 100083, China \\ Correspondence should be addressed to Yan Xiaoqiang; yanxq@ustb.edu.cn
}

Received 11 November 2020; Revised 27 January 2021; Accepted 2 February 2021; Published 16 February 2021

Academic Editor: Alessandro Lidozzi

Copyright (C) 2021 Jia Jinliang and Yan Xiaoqiang. This is an open access article distributed under the Creative Commons Attribution License, which permits unrestricted use, distribution, and reproduction in any medium, provided the original work is properly cited.

\begin{abstract}
Aiming at the power supply problem of high-speed rotating equipment, a wireless power transfer system based on U-shaped core coupling mechanism with a primary coil is proposed. Firstly, the transfer model of the U-type coupling mechanism wireless power transfer system is established. The expressions of transfer power and transfer efficiency are obtained by theoretical calculation, and the factors affecting the transfer characteristics of the system are analyzed. At the same time, the magnetic field distribution of the system and the coupling parameters change when the relative position of the primary and secondary coils changes through simulation analysis. Finally, an experimental platform is established for experimental verification. The results show that the system can obtain 1.72 w output power with $51.19 \%$ transfer efficiency when the distance between the secondary coil and U-core is $15 \mathrm{~mm}$ and $30 \mathrm{~mm}$, respectively. The transmission efficiency and power of the primary coil and secondary coil under different misalignments are tested and compared. It is proved that the wireless power transfer system based on U-type coupling mechanism can effectively realize the stable power supply of the rotating equipment monitoring system.
\end{abstract}

\section{Introduction}

As a new type of power transmission mode, wireless power transfer (WPT) technology has been widely developed in different working environment and application fields with the deepening of its research. In particular, dynamic WPT technology provides wireless power for relative motion equipment, which effectively solves the problems of friction loss, contact arc, and inconvenient installation. WPT technology is an effective and feasible power supply scheme to realize safe, long-term, and stable operation of relative moving equipment $[1-3]$.

For the dynamic wireless power supply of relative moving equipment, the most widely used fields are the dynamic wireless charging of electric vehicles and rail trains and the wireless power supply of rotating equipment. In 2015, Korea Academy of Science and Technology proposed an I-type structure bipolar core track and S-type bipolar core track for wireless power supply of trams. I-core track has the advantages of narrow width, large air gap, higher output power, and low construction cost. The $\mathrm{U}$-core track is smaller than the I-type track, with the maximum efficiency reaching $91 \%$, and the power is $9.5 \mathrm{~kW}[4,5]$. In 2016, Seoul University of South Korea proposed a WPT system with SStype coupling structure and achieved $300 \mathrm{~kW}$ power transfer with $96 \%$ efficiency under $7 \mathrm{~cm}$ air gap through the built experimental platform [6]. In 2016, German Fraunhofer Institute of Integrated Systems and Device Technology proposed an inductive wireless power supply technology for rotating equipment. The system consists of three parts: bearing, rotating shaft, and rotary transformer and sensor load fixed on the shaft. It is small in size and easy to install. It can realize $20 \mathrm{~W}$ wireless power transmission under $89.7 \%$ transfer efficiency [7]. In 2017, Tianjin University of Technology proposed an asymmetric coupling wireless power supply system with single rectangular coil at the transmitter and multisquare coil at the receiving end. A 10:1 reduced experimental model was established, and it was verified that the transfer efficiency of the system could reach $91.4 \%$ and the maximum load power was $139 \mathrm{~W}$ under different coil 
offset degrees when the transfer distance was $5 \mathrm{~cm}$ [8]. In 2018, Harbin Institute of Technology proposed a wireless power supply system for rotating equipment. The system uses a solenoid nested coupling mechanism with a skeleton magnetic core. Through the experimental system, the $3 \mathrm{~kW}$ power level wireless power transfer is realized with $87.1 \%$ transmission efficiency under $1 \mathrm{~cm}$ gap [9]. In 2019, the Institute of Electrical Engineering of Chinese Academy of Sciences designed an omnidirectional three-dimensional receiving resonator in view of the situation that the load end will have angle deflection and offset under special environment in 2019. It can realize all-angle, multiattitude, and high-power wireless power transmission. Through the simulation experiment, when the system offset distance is within the radius, the load power attenuation is less than $25 \%$, which proves that the designed three-dimensional resonance device has a certain antioffset ability [10]. In 2020, Auckland University of New Zealand proposed an inductive WPT system based on active boost bridge inverter for wireless charging of electric vehicles. Compared with the traditional full-bridge system, the system does not need additional switching equipment, reduces switching loss, and can track the maximum efficiency under a wide range of working conditions. The feasibility of the proposed system is verified by the developed $3.5 \mathrm{~kW}$ experimental prototype [11]. In 2020, in order to solve the problem of wireless power supply for equipment on rotating shaft, University of Science and Technology Beijing designed a high-frequency induction power supply system with the primary coil composed of aluminum ring and secondary coil made of PCB. The eddy current loss caused by the central drive shaft of the coil was studied and analyzed. The system has been applied stably in the field with good operation effect [12, 13]. In 2018, the University of Malaya designed a $1 \mathrm{~kW}$ WPT system, which can transmit $1 \mathrm{~kW}$ of power with $90.5 \%$ transmission efficiency and can still guarantee $72 \%$ transmission efficiency under the condition of $40 \%$ misalignments [14]. In 2021, the University of Malaya proposed a three-coil WPT system with $S$-S-LCLCC compensation structure. When the load resistance of the system is $222 \Omega$, the power transmission efficiency of the designed system is $10 \%$ higher than that of the traditional WPT system [15]. The important experimental parameters of the above research results are listed and compared as shown in Table 1.

Aiming at the problem of wireless power supply for rotating equipment, this paper proposes a WPT system based on U-core coupling mechanism in the primary side. Compared with the traditional space planar coil and spiral coil, the primary side $\mathrm{U}$-shaped coupling mechanism can reduce the size of the primary side coil structure and facilitate the installation in a narrow space. The U-shaped core structure can enhance the coupling coefficient and the magnetic field distribution of the power transmission channel. Based on the circuit topology of U-type coupling mechanism WPT system, the expressions of system transmission efficiency and power are derived, the system simulation model is established, the spatial magnetic field distribution of the system is analyzed, and the feasibility of the system is verified by setting up an experimental platform.

\section{WPT System Analysis of U-Type Coupling Mechanism}

The mutual inductance and coupling coefficient between the primary and secondary coils are required in the power transfer process of WPT system, and the mutual inductance and coupling coefficient are related to the relative position and spacing between the primary side and the secondary side. In order to improve the efficiency and output power transfer, it is necessary to design appropriate coupling mechanism to meet the requirements of mutual inductance and coupling coefficient. The structure diagram of WPT system based on U-core coupling structure is shown in Figure 1, in which the primary coil is wound around the U-shaped magnetic core and remains stationary, while the secondary side coil is fixed on the rotating axis and rotates with the shaft.

The U-type coupling mechanism WPT system adopts a series-series (SsS) reactive power compensation circuit topology. The S-S topology structure has simple circuit structure and convenient parameter design. Moreover, the output characteristics of the system are independent of the inductance values of the primary and secondary coils and can output constant current $[16,17]$. The circuit topology of the system is shown in Figure 2. The AC voltage at the input side of the system is transmitted to the inverter after rectification to generate high-frequency $\mathrm{AC}$ voltage as the input voltage of the primary coil. The secondary coil generates high-frequency AC voltage through induction and outputs it to the load side through the rectifier circuit. In Figure 2, US represents AC voltage source, S1, S2, S3, and S4 represent switch tube of inverter circuit, $\mathrm{C} 1$ and $\mathrm{C} 2$ represent resonance compensation capacitance of the primary side and secondary side, respectively, L1 and L2 represent coil selfinductance of the primary side and secondary side, respectively, $M$ represents mutual inductance of the primary side and secondary side coil, and RL represents equivalent resistance value of load.

In order to calculate the transfer efficiency and power of the system, let $R_{1}=R_{\mathrm{S}}+R_{\mathrm{Tx}}, X_{1}=L_{1}+1 / \omega C_{1}, R_{2}=R_{\mathrm{L}}+R_{\mathrm{Rx}}$, and $X_{2}=L_{2}+1 / \omega C_{2}$, where $R_{\mathrm{S}}$ is the internal resistance of the voltage source, $R_{\mathrm{TX}}$ and $R_{\mathrm{RX}}$ are the equivalent resistance of the primary side and the secondary side, respectively, and $\omega$ is the working angular frequency of the system. The primary and secondary loop impedances can be expressed as follows:

$$
\left\{\begin{array}{l}
Z_{1}=R_{1}+\mathrm{j} \mathrm{X}_{1} \\
Z_{2}=R_{2}+\mathrm{jX}
\end{array}\right.
$$

The reflection impedance of the primary and secondary circuits can be expressed as follows:

$$
\left\{\begin{array}{l}
Z_{1}^{\prime}=\frac{(\omega M)^{2}}{Z_{2}}=\frac{(\omega M)^{2}}{R_{2}+\mathrm{j} \mathrm{X}_{2}}=R_{1}^{\prime}+\mathrm{jX} \mathrm{X}_{1}^{\prime}, \\
Z_{2}^{\prime}=\frac{(\omega M)^{2}}{Z_{1}}=\frac{(\omega M)^{2}}{R_{1}+\mathrm{jX}_{1}}=R_{2}^{\prime}+\mathrm{jX}_{2}^{\prime} .
\end{array}\right.
$$

Among them, 
TABLE 1: System parameters.

\begin{tabular}{|c|c|c|c|}
\hline Institution & Gap & $P(\mathrm{~kW})$ & $\eta(\%)$ \\
\hline Korea Institute of Science and Technology & $20 \mathrm{~cm}$ & 9.5 & 91 \\
\hline Korea Institute of Science and Technology & $7 \mathrm{~cm}$ & 300 & 96 \\
\hline Fraunhofer Institute of Integrated Systems and Device Technology & $3 \mathrm{~mm}$ & 20 & 89.7 \\
\hline Tianjin Polytechnic University & $5 \mathrm{~cm}$ & 139 & 91.4 \\
\hline Harbin Institute of Technology & $1 \mathrm{~cm}$ & 3 & 87.1 \\
\hline Institute of Electrical Engineering, Chinese Academy of Sciences & $16 \mathrm{~cm}$ & 80 & 88 \\
\hline University of Auckland & $15 \mathrm{~cm}$ & 2.2 & 95.4 \\
\hline University of Malaya & $150 \mathrm{~mm}$ & 1 & 90.5 \\
\hline University of Malaya & - & 420 & 91.2 \\
\hline
\end{tabular}

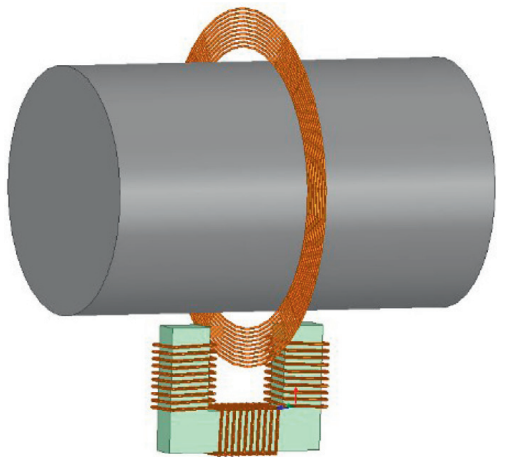

FIGURE 1: Schematic diagram of U-type coupling structure WPT system.

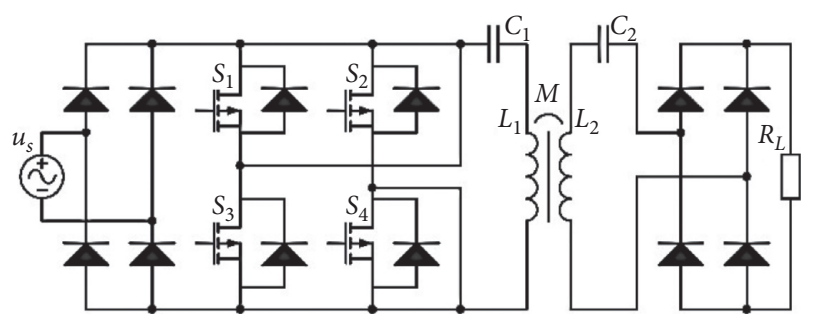

FIgURE 2: System circuit topology.

$$
\left\{\begin{array}{l}
R_{1}^{\prime}=\frac{(\omega M)^{2}}{R_{2}^{2}+X_{2}^{2}} R_{2} \\
X_{1}^{\prime}=-\frac{(\omega M)^{2}}{R_{2}^{2}+X_{2}^{2}} X_{2} \\
R_{2}^{\prime}=\frac{(\omega M)^{2}}{R_{1}^{2}+X_{1}^{2}} R_{1} \\
X_{2}^{\prime}=-\frac{(\omega M)^{2}}{R_{1}^{2}+X_{1}^{2}} X_{1} .
\end{array}\right.
$$

From formula (1) and equation (3), the total impedance of the primary and secondary circuits can be obtained as follows:

$$
\left\{\begin{array}{l}
Z_{\mathrm{Tx}}=Z_{1}+Z_{1}^{\prime}, \\
Z_{\mathrm{Rx}}=Z_{2}+Z_{2}^{\prime} .
\end{array}\right.
$$

According to KVL and KCL, the primary and secondary loop current expressions are as follows:

$$
\left\{\begin{array}{l}
I_{1}=\frac{1}{Z_{\mathrm{Tx}}+\left((\omega M)^{2} / Z_{\mathrm{Rx}}\right)} U_{S}, \\
I_{2}=-\frac{j \omega M}{Z_{\mathrm{Tx}} Z_{\mathrm{Rx}}+(\omega M)^{2}} U_{S} .
\end{array}\right.
$$

The output power and transfer efficiency of the system can be obtained as follows:

$$
\left\{\begin{array}{l}
P_{\text {out }}=\frac{U_{S}^{2} R_{L}}{\left[\left(Z_{1} Z_{2} / \omega M\right)+\left((\omega M)^{3} / Z_{1} Z_{2}\right)+3(\omega M)\right]^{2}}, \\
\eta=\frac{U_{S} R_{L}}{\left(Z_{1} Z_{2}^{2} /(\omega M)^{2}\right)+\left((\omega M)^{4} / Z_{1}^{2} Z_{2}\right)+\left(4(\omega M)^{2} / Z_{1}\right)+4 Z_{2}} .
\end{array}\right.
$$

It can be seen from equation (6) that when the system parameters have been determined, the main factors affecting the output power and transfer efficiency of the system are the resonance frequency and mutual inductance of the system, and the mutual inductance is closely related to the relative distance between the primary and secondary coils. Therefore, the change trend of transfer efficiency and power can be found by studying the change of relative distance between the primary coil and secondary coil.

\section{Simulation and Analysis of Electromagnetic Parameters of U-Type Coupling Mechanism WPT System}

In order to study the influence of the relative position of the system on the mutual inductance and coupling coefficient, it is necessary to understand the distribution of the magnetic induction intensity of the system. The parameters in Table 2 were used for modeling and analysis.

The distribution diagram of magnetic induction intensity around the primary side coil based on U-shaped magnetic core is shown in Figure 3. It can be seen from 
TABLE 2: System parameters.

\begin{tabular}{lc}
\hline Parameter & Value \\
\hline Core opening width $(\mathrm{mm})$ & 60 \\
Core opening height $(\mathrm{mm})$ & 60 \\
Cross-sectional area of magnetic core $\left(\mathrm{mm}^{2}\right)$ & 600 \\
Primary coil diameter $(\mathrm{mm})$ & 2 \\
Primary coil turns (turn) & 30 \\
Cross-sectional area of secondary coil $\left(\mathrm{mm}^{2}\right)$ & 0.25 \\
Secondary coil turns (turn) & 9 \\
Inner diameter of secondary coil $(\mathrm{mm})$ & 100 \\
\hline
\end{tabular}

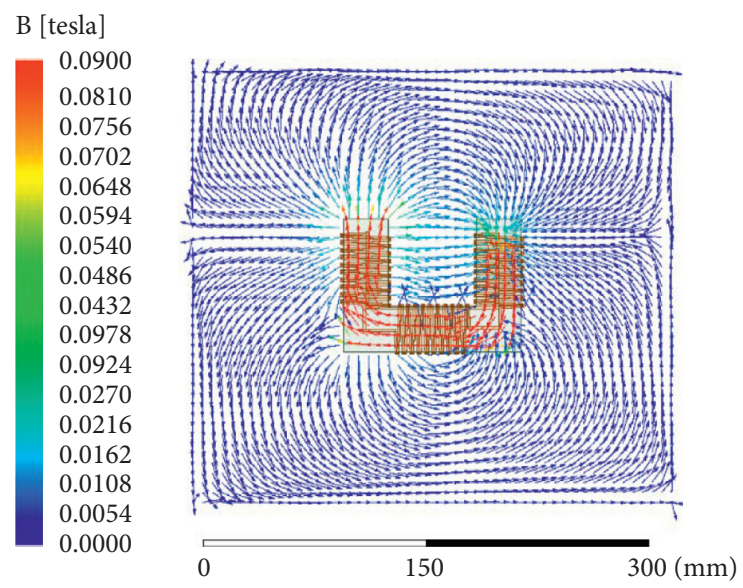

FIGURE 3: Distribution of magnetic induction intensity of the primary U-shaped core coil.

Figure 3 that the magnetic field around the primary side coil based on the U-core is symmetrically distributed. The magnetic induction intensity inside the core is the highest, and the opening of the magnetic core decreases, and finally a closed magnetic field loop is formed. The maximum magnetic induction intensity inside the core can reach $390 \mathrm{mT}$, the magnetic induction intensity at the opening of the core is mainly about $10 \mathrm{mT}$, and the maximum magnetic induction intensity at the opening can reach $100 \mathrm{mT}$.

When studying the influence of the relative position of the coils on the mutual inductance and coupling coefficient of the system, the variation law of the mutual inductance and coupling coefficient is explored by changing the transverse distance $d$ and the longitudinal distance $h$ between the primary coil and the secondary coil, as shown in Figure 4. In order to avoid the interference between the primary and secondary coils caused by high-speed rotation, $d=15 \mathrm{~mm}$ and $h=15 \mathrm{~mm}$ are taken as the minimum reference spacing, and the parameters shown in Table 2 are used for modeling analysis and physical production.

Set $d=30 \mathrm{~mm}$ and $h=30 \mathrm{~mm}$ as the initial standard spacing; the electromagnetic parameters of coupling mechanism are measured by Maxwell electromagnetic simulation and RLC bridge meter under the initial standard spacing, as shown in Table 3. From the data in Table 3, it can be seen that the simulation results and the actual measured values are basically the same, and the maximum error is only $3.03 \%$. When the system operating frequency changes from
$100 \mathrm{kHz}$ to $300 \mathrm{kHz}$, the self-inductance and mutual inductance of the coil have little difference. Therefore, in the later analysis, $f=200 \mathrm{kHz}$ can be used as the system operating frequency for analysis and research.

When the working frequency of the system is $200 \mathrm{kHz}, d$ and $h$ are fixed, respectively. According to the simulation calculation, with the distance $d$ and $h$ changing, respectively, the mutual inductance between the coils changes, and the change trend is shown in Figure 5. It can be seen from Figure 5 that when the secondary side coil moves to the right, the change of mutual inductance $M$ is not obvious. When the coil moves to the right for $15 \mathrm{~mm}$, the mutual inductance increases by $0.2 \mu \mathrm{H}$ and $1.21 \%$. When the secondary coil moves downward, the mutual inductance changes obviously. When the coil moves $15 \mathrm{~mm}$, the mutual inductance increases by $4.28 \mu \mathrm{H}$ and $25.90 \%$. Therefore, the maximum efficiency and output power of the system can be improved by moving the secondary coil up and down to make the system mutual inductance to the maximum value.

It can be concluded from the above analysis that the change of $d$ has little effect on mutual inductance. In order to keep a large distance between the primary and secondary coils in the horizontal direction, $d=30 \mathrm{~mm}$ can always be maintained, and the system can obtain the maximum mutual inductance $M=20.81 \mu \mathrm{H}$ at $h=15 \mathrm{~mm}$ under the condition of minimum reference distance in vertical direction. Therefore, $d=30 \mathrm{~mm}$ and $h=15 \mathrm{~mm}$ are selected as the maximum mutual inductance position of the system. At this time, the distribution of magnetic induction intensity of the system is shown in Figure 6. It can be seen from Figure 6 that the magnetic induction intensity around the primary coil is the largest near the opening of the U-shaped core, which is about $10 \mathrm{mT}$.

\section{Simulation Analysis and Experimental Research}

Based on the above analysis results, this paper selects $d=30 \mathrm{~mm}$ and $h=15 \mathrm{~mm}$ as the relative position of the primary side and secondary side and uses Maxwell and Simplorer software to establish the model based on the structural parameters in Table 1 for joint simulation analysis. The joint simulation model is shown in Figure 7.

The specific parameters of the system circuit in the simulation model are shown in Table 4.

The input voltage, current, output voltage, and current waveforms of the system are shown in Figure 8.

Figure 8 (a) shows the input voltage and current waveforms of the system simulation. It can be seen that the voltage and current are basically in phase. After several cycles, the current reaches a stable state, and the peak value can be stabilized at $560 \mathrm{~mA}$. Therefore, the input power can be estimated as $4.20 \mathrm{~W}$. Figure 8 (b) shows the output voltage and current waveforms of the system before rectification. It can be seen that the output voltage and current are in inverse phase with the input voltage and current waveform. After several cycles, the voltage and current reach a stable state. The peak values of voltage and current are, respectively, stabilized at $10.4 \mathrm{~V}$ and $530 \mathrm{~mA}$, and the output power is 


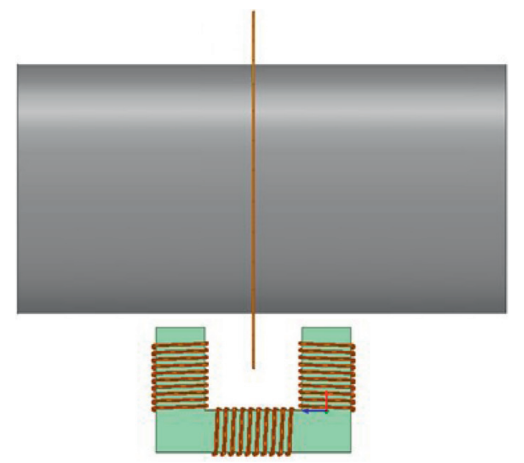

FIGURE 4: Schematic diagram of relative position between the secondary coil and primary coil.

TABLE 3: Simulation and measured electromagnetic parameters of coupling mechanism under initial standard spacing.

\begin{tabular}{llccc}
\hline Parameter & & Simulation value $/ \mu \mathrm{H}$ & Experimental values/ $\mu \mathrm{H}$ & Error value $(\%)$ \\
\hline \multirow{2}{*}{$L_{1}$} & $f=100 \mathrm{kHz}$ & 122.91 & 120.79 & 1.72 \\
& $f=200 \mathrm{kHz}$ & 122.81 & 120.52 & 1.86 \\
\hline \multirow{2}{*}{$L_{2}$} & $f=300 \mathrm{kHz}$ & 122.78 & 44.35 & 1.75 \\
\hline & $f=100 \mathrm{kHz}$ & 45.15 & 44.32 & 1.77 \\
& $f=200 \mathrm{kHz}$ & 45.14 & 44.28 & 1.82 \\
& $f=300 \mathrm{kHz}$ & 45.14 & 16.12 & 1.91 \\
\hline & $f=100 \mathrm{kHz}$ & 16.54 & 16.06 & 2.54 \\
& $f=200 \mathrm{kHz}$ & 16.53 & 16.01 & 3.84 \\
\hline
\end{tabular}

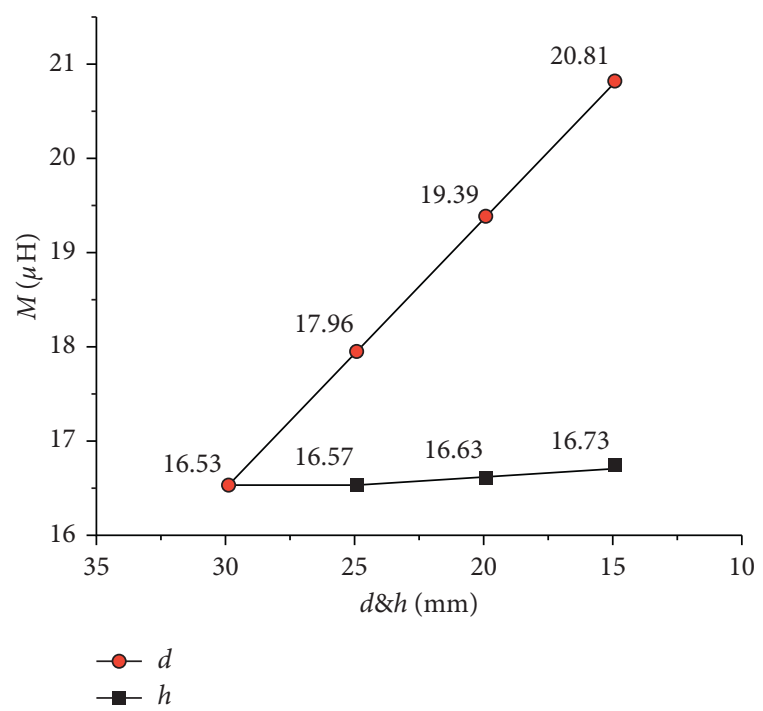

Figure 5: Variation trend of coil mutual inductance.

$2.76 \mathrm{~W}$. In conclusion, the simulation output efficiency of the system is $65.71 \%$.

According to the above simulation results, an experimental platform of the $\mathrm{U}$-shaped coupling mechanism radio power transmission system is built as shown in Figure 9. The size parameters of system coupling mechanism are shown in Table 1, and the parameters of system circuit components are shown in Table 4. In the experiment, UTP3705 S is used as DC power supply, UTD2112CEX oscilloscope is used for waveform detection, and VC4092D digital bridge meter is
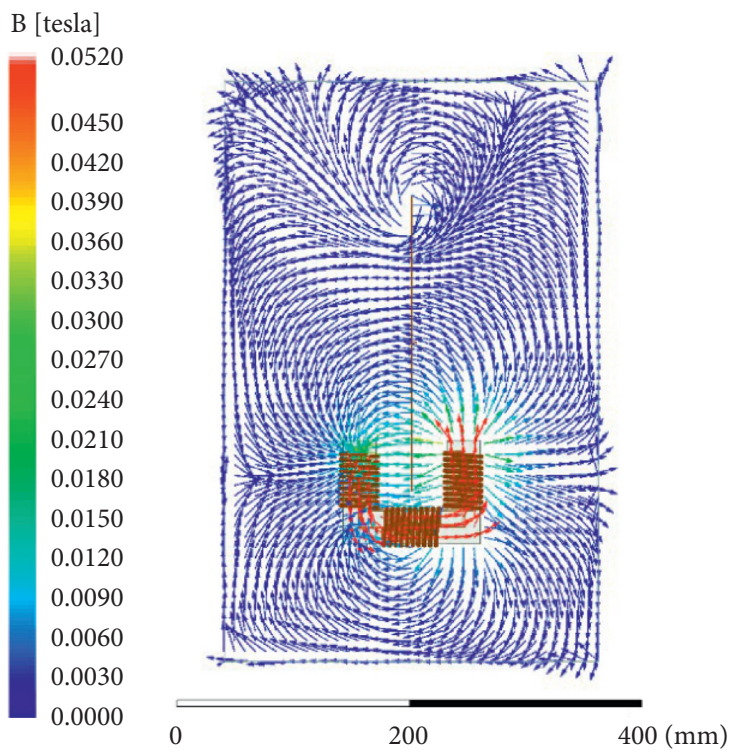

Figure 6: Distribution of magnetic induction intensity.

used to measure the inductance, capacitance, impedance, and other parameters of the system.

The self-inductance and mutual inductance values of the primary and secondary coils measured by VC4092D digital bridge meter are shown in Table 3. The primary side input voltage waveform and secondary side output voltage waveform are measured by oscilloscope, as shown in Figure 10. The amplitude of primary side input voltage 


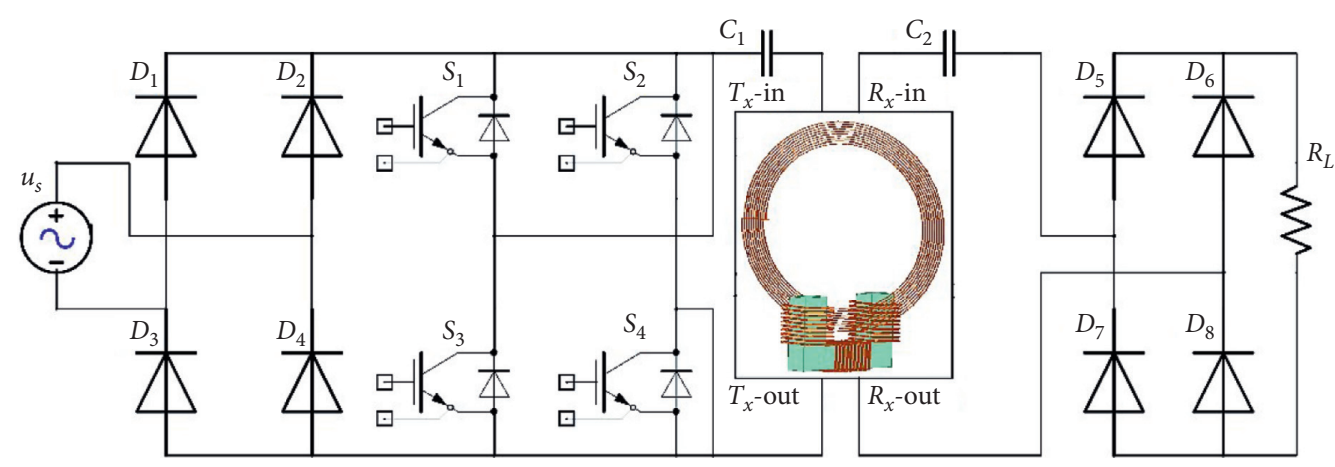

Figure 7: Joint simulation model.

TABle 4: System circuit parameters.

\begin{tabular}{lr}
\hline Parameter & Value \\
\hline$f(\mathrm{kHz})$ & 200 \\
$L_{1}(\mu \mathrm{h})$ & 120.52 \\
$R_{\mathrm{Tx}}(\mathrm{m} \Omega)$ & 328.74 \\
$C_{1}(\mathrm{nF})$ & 5.25 \\
$L_{2}(\mu \mathrm{h})$ & 44.32 \\
$R_{\mathrm{Rx}}(\mathrm{m} \Omega)$ & 511.12 \\
$C_{2}(\mathrm{nF})$ & 14.29 \\
$R_{\mathrm{L}}(\Omega)$ & 100 \\
Input AC voltage peak $(\mathrm{V})$ & 15 \\
\hline
\end{tabular}

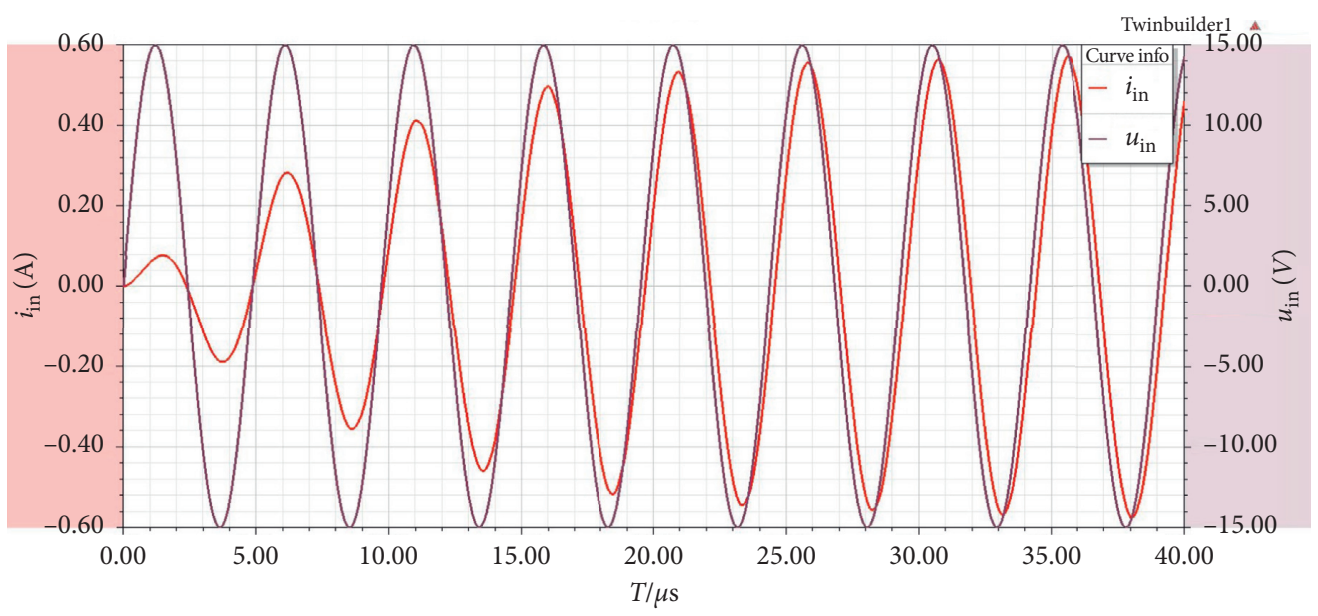

(a)

Figure 8: Continued. 


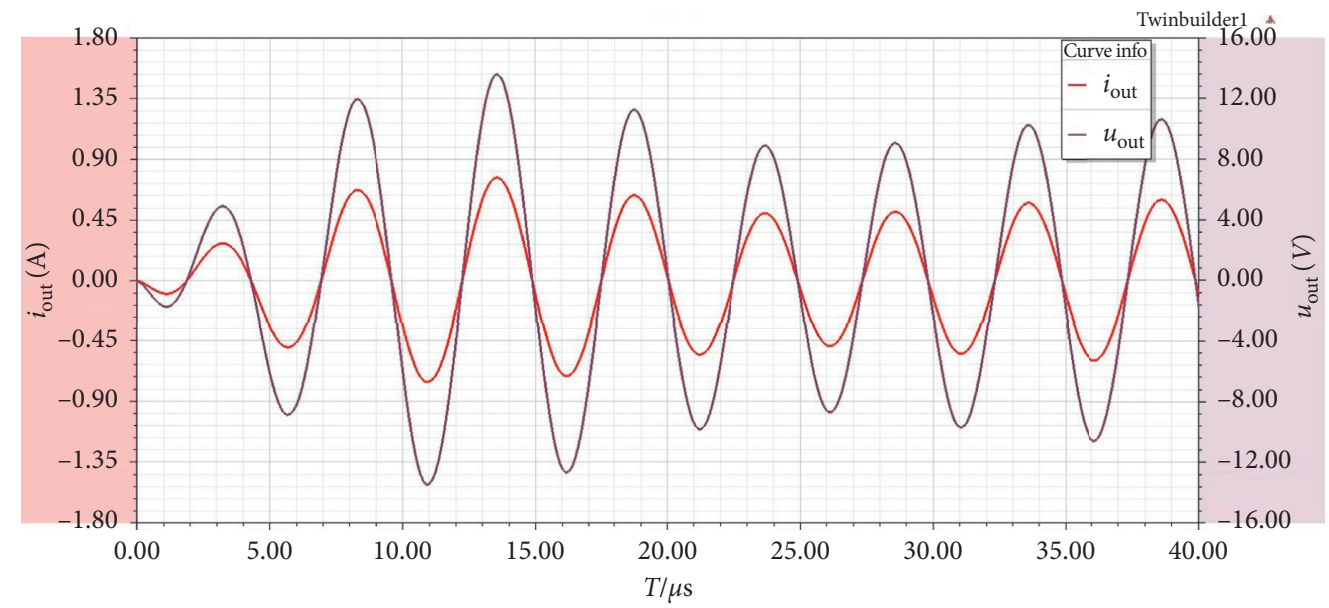

(b)

FIGURE 8: Waveform of simulation voltage and current. (a) Input voltage and current waveform. (b) Output voltage and current waveform.

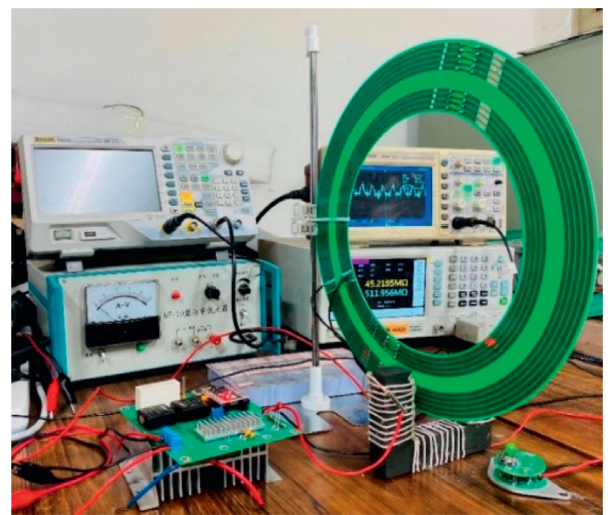

FIGURE 9: Experimental platform of the U-type coupling mechanism wireless power transfer system.

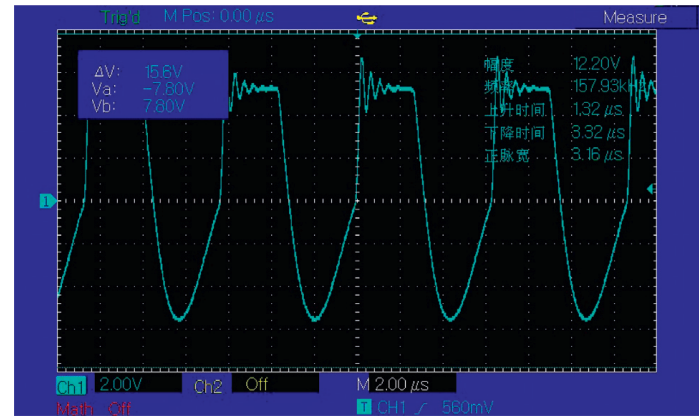

(a)

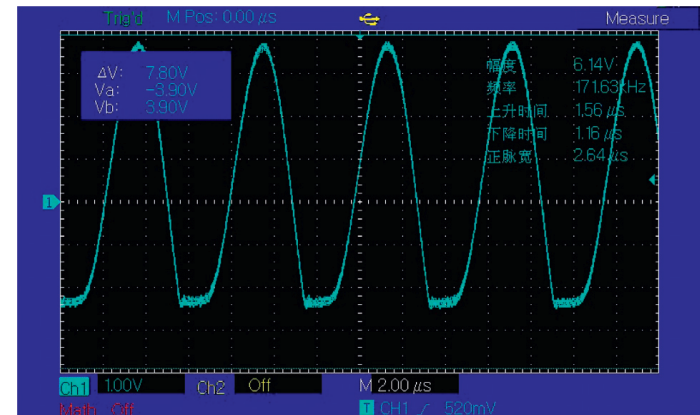

(b)

FIgURe 10: Experimental voltage waveform. (a) Primary side input voltage waveform. (b) Secondary side output voltage waveform.

waveform is about $12.2 \mathrm{~V}$, and the amplitude of secondary side output voltage waveform is about $6.14 \mathrm{~V}$.

The input power and output power of the system can be obtained by measuring the input power of the DC power supply at the primary side and the power consumed by the load at the secondary side. The input power of the system is the input power of the inverter circuit of the primary side circuit, and the output power of the system is the power input to the load after the secondary side rectification. The input power and output power of the system are $3.36 \mathrm{~W}$ and $1.72 \mathrm{~W}$, respectively. The transfer efficiency of the system is $51.19 \%$. Compared with the results of simulation and experiment, the difference of transfer efficiency between simulation and experiment is $14.52 \%$. Because the transfer efficiency measured by experiment includes the power loss caused by inverter and rectifier, while the transfer efficiency 


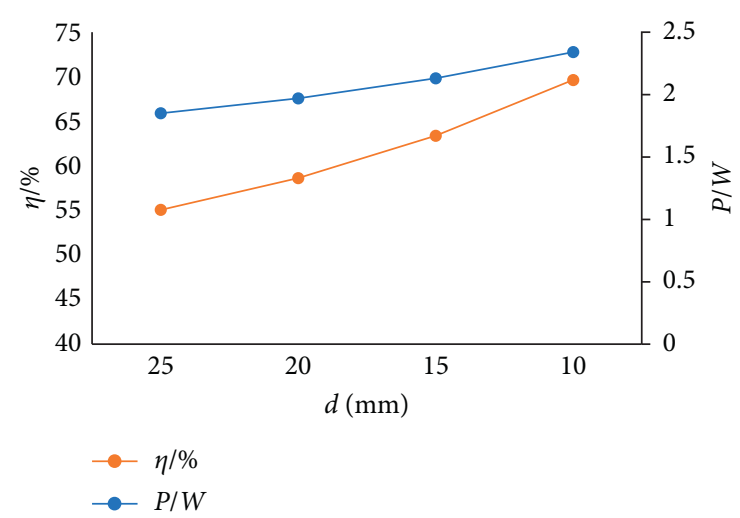

FIgURE 11: Comparison of experimental results.

of simulation part does not calculate the loss of these two parts, the transfer efficiency of experimental results is smaller than that of simulation analysis.

When the relative distance between the primary and secondary coils of the system is $d=25 \mathrm{~mm}, d=20 \mathrm{~mm}, d=15 \mathrm{~mm}$, and $d=10 \mathrm{~mm}$, the comparison results are shown in the figure.

It can be seen from Figure 11 that when the relative position between the primary coil and the secondary coil changes, the transmission efficiency and transmission power of the system change. With the decrease of the distance $d$, the transmission efficiency and transmission power gradually increase, but the decrease of the distance increases the risk of collision between the primary coil and the secondary coil. Therefore, the distance $d$ between the primary coil and the secondary coil is still set as $30 \mathrm{~mm}$; it is the optimal relative position between the primary and secondary coils.

In summary, although there are some differences between the experimental results and the simulation results, through the simulation analysis and experimental verification, it can be seen that the U-type coupling mechanism wireless power transfer system can effectively realize the wireless transfer of electric energy, which provides a good solution for wireless power supply of high-speed rotating shaft equipment.

\section{Conclusion}

In this paper, a WPT system based on U-type magnetic core coupling mechanism is proposed. Through theoretical analysis, simulation analysis, and experimental verification, the following conclusions are obtained: (1) the relative distance between the primary U-core coupling mechanism and the secondary coil affects the mutual inductance and coupling coefficient of the system, thus affecting the transfer efficiency and output power of the system; (2) electromagnetic simulation shows that the magnetic field of the system is mainly distributed near the opening of the U-shaped core; (3) the experimental results show that the transfer efficiency of the system can reach $51.19 \%$, and the output power is $1.72 \mathrm{~W}$, which verifies the feasibility of the U-shaped magnetic core coupling structure to realize wireless power transfer. The conclusion of this paper provides theoretical basis and application guidance for the application of U-core coupling mechanism wireless power transfer. There is still room for improvement and optimization. How to improve the transfer efficiency and output power of the system is the direction of further research in the follow-up work.

\section{Data Availability}

The datasets supporting the conclusions of this article are included within the article.

\section{Conflicts of Interest}

The authors declare that they have no conflicts of interest.

\section{Acknowledgments}

This work was financially supported by the "12th Five-Year" National Science and Technology Support Plan, "Precision Strip Steel Product Quality Optimization and Key Equipment Research and Development" (Grant no. 2015BAF30B00), and "Fundamental Research Funds for the Central Universities" (Grant no. FRF-AT-19-001).

\section{References}

[1] C. H. Zhu, J. H. Jiang, K. Song et al., "Research progress of key technologies for dynamic wireless charging of electric vehicle," Automation of Electric Power Systems, vol. 41, no. 2, pp. 60-65, 2017.

[2] B. Zhang, X. J. Shu, L. H. Wu et al., "Problems of wireless power transmission technology urgent to be solved and corresponding counter measures," Automation of Electric Power Systems, vol. 43, no. 18, pp. 1-12, 2019.

[3] L. H. Wu, P. Sun, S. H. Yang et al., "Review on underwater wireless power transfer technology and its application," Transactions of China Electrotechnical Society, vol. 34, no. 8, pp. 1559-1568, 2019.

[4] C. Park, S. Lee, S. Y. Jeong, G.-H. Cho, and C. T. Rim, "Uniform power I-type inductive power transfer system with DQ-power supply rails for on-line electric vehicles," Institute of Electrical and Electronics Engineers Transactions on Power Electronics, vol. 30, no. 11, pp. 6446-6455, 2015.

[5] S. Y. Choi, S. Y. Jeong, B. W. Gu, G. C. Lim, and C. T. Rim, "Ultraslim S-type power supply rails for roadway-powered electric vehicles," Institute of Electrical and Electronics Engineers Transactions on Power Electronics, vol. 30, no. 11, pp. 6456-6468, 2015.

[6] S.-H. Lee, B.-S. Lee, and J.-H. Lee, “A new design methodology for a $300-\mathrm{kW}$, low flux density, large air gap, online wireless power transfer system," Institute of Electrical and Electronics Engineers Transactions on Industry Applications, vol. 52, no. 5, pp. 4234-4242, 2016.

[7] S. Ditze, A. Endruschat, T. Schriefer et al., "Inductive power transfer system with a rotary transformer for contactless energy transfer on rotating applications," in IEEE International Symposium on Circuits and Systems, pp. 1622-1625, Montreal, CA, USA, May, 2016.

[8] C. Y. Yuan, X. Zhang, Q. X. Yang et al., “Asymmetric coupling mechanism of wireless power transmission system for highspeed train technology," Transactions of China Electrotechnical Society, vol. 32, no. 18, pp. 18-25, 2017. 
[9] B. Q. Ma, "Research on Wireless Power Transfer Technology Applied to Rotating Equipment," Harbin Institute of Technology, Harbin, China, 2016.

[10] H. L. An, G. Q. Liu, Y. H. Li et al., "The characteristics study of three dimension anti deflection magnetic coupling resonance wireless energy transmission resonator," Transactions of China Electrotechnical Society, vol. 34, no. 13, pp. 2679-2685, 2019.

[11] G. R. Kalra, D. J. Thrimawithana, B. S. Riar, C.-Y. Huang, and M. Neuburger, "A novel boost active bridge-based inductive power transfer system," Institute of Electrical and Electronics Engineers Transactions on Industrial Electronics, vol. 67, no. 2, pp. 1103-1112, 2020.

[12] J. L. Jia and X. Q. Yan, "Application of magnetic coupling resonant wireless power supply in a torque online telemetering system of a rolling mill," Journal of Electrical and Computer Engineering, vol. 2020, 2020.

[13] J. L. Jia and X. Q. Yan, "Research on wireless power transmission characteristics of the torque telemetry system under the influence of rolling mill drive shaft," UPB Scientific Bulletin, Series C: Electrical Engineering and Computer Science, vol. 82, no. 1, pp. 315-327, 2020.

[14] K. A. Kalwar, M. Aamir, and S. Mekhilef, "A design method for developing a high misalignment tolerant wireless charging system for electric vehicles," Measurement, vol. 118, pp. 237-245, 2018.

[15] P. Darvish, S. Mekhilef, and H. A. B. Illias, "A novel S-S-lclcc compensation for three-coil WPT to improve misalignment and energy efficiency stiffness of wireless charging system," Institute of Electrical and Electronics Engineers Transactions on Power Electronics, vol. 36, no. 2, pp. 1341-1355, 2021.

[16] Y. Zhang, Z. Yan, Z. Liang, S. Li, and C. C. Mi, "A high-power wireless charging system using LCL-N topology to achieve a compact and low-cost receiver," Institute of Electrical and Electronics Engineers Transactions on Power Electronics, vol. 35, no. 1, pp. 131-137, 2020.

[17] X. Dai, Y. Sun, C. S. Tang et al., Wireless Power Transfer technology, Science Press, Beijing, China, 2017. 